\title{
Endocervical Curettage
}

National Cancer Institute

\section{Source}

National Cancer Institute. Endocervical Curettage. NCI Thesaurus. Code C15403.

A procedure in which the mucous membrane of the cervical canal is scraped using a curette. 